DESCOLA, Philippe. La composition des mondes: entretiens avec Pierre Charbonnier. Paris: Flammarion, 2014. 381 p.

\title{
Jean Segata
}

Universidade Federal do Rio Grande do Norte E-mail: jeansegata@gmail.com

Dhilippe Descola tem sido apontado como um dos mais importantes antropólogos dos últimos anos. De suas pesquisas resultou o aparecimento de diversos trabalhos que se dispõem à discussão, à evidência ou à apresentação de sua obra. Esse é o caso de La composition des mondes, fruto de entrevistas com o jovem filósofo Pierre Charbonnier, chargé de recherche no Institut Marcel Mauss da École des Hautes Études en Sciences Sociales (EHESS). Charbonnier tem se dedicado ao estudo das noções de natureza, ecologia e ambiente na antropologia, o que faz da obra de Philippe Descola uma de suas interlocuções privilegiadas, como aquela que acontece em seu outro recente trabalho, intitulado $\mathrm{La}$ fin d'un grand partage: nature et société, de Durkheim à Descola (publicado em 2015, pela CNRS Édition - Paris).

Como é o caso comum em publicações resultantes de entrevistas, La composition des mondes coloca o leitor à vontade com o texto e o oportuniza a uma aproximação mais íntima com o autor e seu percurso intelectual. É o que se nota nos dois primeiros capítulos, Le goût de l'enquete e Le séjour amazonien et les enjeux de l'ethnographie au long cours. Além da já conhecida filiação à Claude Lévi-Strauss, orientador de sua tese de doutorado defendida em 1983 e publicada em 1986, como La Nature Domestique: symbolisme et praxis dans l'écologie des Achuar, na qual, em geral, se situa o ponto de início do projeto antropológico de Philippe Descola, nesses dois primeiros capítulos de La composition des mondes ele reconstitui o caminho que o faz chegar a esse ponto, suas 
inspirações particulares, a política e o cenário acadêmico da França dos anos de 1960-1970.

Com uma infância marcada pelo gosto pela literatura do exótico, Descola rememora a leitura de Le tour de monde (uma coleção que ele define como sendo uma espécie de National Geographic à francesa), os diários de Charles Darwin ou as novelas de Jules Verne. Não menos importante aparecem em sua biografia as viagens com seus pais à Espanha, ao Reino Unido, ao Canadá ou aos Pirineus, e suas primeiras aventuras de adolescência - "mochileiro" e intercambista - na Inglaterra, Estados Unidos, Turquia e Síria. São momentos descritos em detalhes como parte de seu gosto pela descoberta, que o levaria mais tarde à antropologia.

Na sequência do percurso intelectual aparece sua formação na École Normale Supérieure (ENS), que é situada no contexto de uma academia francesa que já respirava com dificuldade o marxismo e o leninismo, o que responde assim por seu engajamento político de estudante e, ao mesmo tempo, por seu descontentamento com a filosofia, curso de sua formação inicial. Com excessão de Althusser, a esquerda clássica na filosofia perdia lugar para as novidades (não menos entusiasmantes) que se podia encontrar em cursos como o Capitalisme et Schizophrénie, oferecidos por Gilles Deleuze em Saint-Cloud ou aqueles "de um primeiro Michel Foucault", no Collège de France. Nessa época, não como exceção, Descola já era leitor de Lévi-Strauss, que àquela altura já era consolidado como "o grande antropólogo" cujo portfólio já incluía As Estruturas Elementares do Parentesco, O Pensamento Selvagem, a tetralogia Mitológicas, a cadeira de Antropologia Social no Collège de France, a criação do laboratório (unidade mista do Collège de France e da EHESS) e da revista $L^{\prime}$ Homme. Mas, antes de sua aproximação direta com ele, Descola nos faz conhecer uma parte muito interessante da formação em antropologia na França dos 1970, que ele classifica como padecente de raros cursos. Acostumados que somos a situar a formação antropológica francesa com os cursos de etnologia oferecidos por Marcel Mauss depois que ele, Paul Rivet e Lucien Lévy-Bruhl criam o Institut d'ethologie em 1925, causa admiração o cenário colocado por Descola. Há, na sua descrição, três cursos sistemáticos de formação em 
etnologia/antropologia, dos quais ele se liga a dois em seu percurso: um em Nanterre (atual, Université de Paris X - "La Défense"), com a supervisão de Maurice Godelier e Jacques Soustelle e outro na École Pratique des Hautes Études (EPHE) - no âmbito do Formation à la Recherche en Antropologia Sociale et Ethnologie (FRASE) - onde faz seu seu doutorado - troisième cycle. Nesse último, é possível ver professores listados por Descola, cujos nomes são de grande envergadura na disciplina, como o próprio Maurice Godelier (antropologia econômica), Isac Chiva (antropologia rural), Pierre Clastres (antropologia política), Olivier Herrenschmidt (antropologia religiosa), Robert Cresswell (etnologia das técnicas) e Louis Dumont e Simone Dreyfus (parentesco). Porém, para além desses cursos, além da cadeira de Lévi-Strauss no Collège de France, Descola faz referência a um curso de formação oferecida na Sorbonne sob a direção de André Leroi-Gourhan, completava o cenário francês da época. Esses raros cursos, sugere Descola, não fazem dele uma exceção entre os etnólogos de sua geração e daquelas anteriores, vindos de outras áreas, particularmente, da filosofia. Condição que fez com que muitos deles fossem a campo e fizessem suas teses em antropologia sem passar por uma formação específica na disciplina.

Foi o curso de formação em Nanterre - um equivalente ao Diplôme d'Études Approfondies (DEA), que consolida o primeiro ano de doutorado - que exigiu de Descola um exercício prático, de campo, que ele fez acompanhado daquela que viria ser a sua futura esposa, a antropóloga Anne-Christinne Taylor. Em um primeiro momento, eles ensaiam um estudo sobre bruxaria no meio rural no interior da França (village du Lot) e em seguida, em 1973, seguem para o México, onde tratam de relações interétnicas e ocupações rurais em ecossistemas de floresta, ao sul da região de Chiapas. Ali, Descola ainda se vê no engajamento político através da discussão sobre a propriedade e o colonialismo, como também passa a se ver atraído pela ecologia e pela América, para onde voltaria entre 1976 e 1979 para seu trabalho de campo do doutorado, agora entre os Achuar, grupo Jivaro do alto Pastaza, no Equador.

Fortemente inspirado por um célebre artigo de André-Georges Haudricourt, Domestication des animaux, culture des plantes e traitement d'autrui, decidido a se contrapor ao materialismo simplista e redutor 
da ecologia adaptativa de Marvin Harris e não menos insatisfeito pela tese da chefia sem poder da obra de Pierre Clastres, ambos vigentes à época, o trabalho que resulta em La Nature Domestique ressoa rápido na antropologia sob muitas formas. De modo direto, o trabalho fornece novas perspectivas às discussões ecológicas, já que centrado em um sistema de objetivação dos outros, notadamente os não humanos como plantas e animais, foge de um determinismo técnico ou de ambiente implicando no entendimento das condições objetivas de produção do laço social. Os não humanos não são um cenário que condicionam formas sociais, eles são constituintes da relação. Nas palavras de Descola (2014, p. 80-81, tradução nossa)

[...] trata-se de uma tentativa de não separar as modalidades de uso do meio de outras formas de representação, de modo a mostrar como a prática social da natureza se articula de diversas formas à ideia que uma sociedade faz dela mesma, sobre a ideia que ela faz do seu ambiente e sobre a ideia que ela faz de sua intervenção nesse ambiente.

Assim, o "mundo natural" não é uma externalidade ou cenário e os não humanos não são coadjuvantes que condicionam formas sociais, eles são um continuum e parte da relação. O reconhecimento desse trabalho é parte fundamental, alega Descola, na sua rápida projeção acadêmica, que inclui um posto efetivo na EHESS e, por conseguinte, no Laboratoire, já em 1984, como também a condição de visitante em diversas instituições estrangeiras, culminando em 1997 com a apresentação de sua candidatura ao Collège de France, instigada por Françoise Héritier e apresentada pelo antropólogo Nathan Wachtel e pelo neurobiólogo Jean-Pierre Changeux. Nomeado, em 1999, na cadeira de Antropologia da Natureza, ele assume a representação da disciplina naquela prestigiosa instituição desde 2000, numa linha de sucessões que inclui a própria Héritier (Étude comparée des sociétés africaines, 1982-1998), Claude Lévi-Strauss (Anthropologie sociale, 19591982) ou mesmo Marcel Mauss (Sociologie, 1931-1942). Mas, é também desde La Nature Domestique que Descola situa o início de seu projeto antropológico maior, que culminaria na publicação de Par-delà nature et culture, em 2005, em que ele sistematiza quatro modelos ontológicos ou disposições do ser, que permitem a antropologia organizar em um nível 
estrutural o mote que dá nome a esse livro de entrevistas, a composição dos mundos. Para a discussão desse projeto ficam dedicados os terceiro e quarto capítulos que terminam por compor o livro. São intitulados, respectivamente, de La diversité des natures e Le monde contemporain à la lumière de l'anthropologie.

Desde sua etnografia entre os Achuar, Descola afirma descobrir que o tratamento dos "seres da natureza" como sendo investidos de propriedades sociais não era algo próprio apenas deles ou de muitos dos povos ameríndios, mas uma disposição corrente em diversas regiões do mundo, o que lhe instigou, logo de início, a "ressuscitar" o termo animismo. O passo contrastivo ao animismo veio do investimento longo de seu mentor, Lévi-Strauss, no entendimento dos grupos totêmicos, sobre os quais Descola valorizará, sobremaneira, a compreensão de disposições contínuas de fisicalidade entre humanos e não humanos, como a precisão de caça do jaguar, a habilidade e silêncio da sucuri ao se locomover na selva, ainda que sejam descontinuados moralmente. Mas, além da inovação de pensar esses dois modelos como sendo ontologias, o que seria o cerne da inovação de seu projeto seria a postulação de outras duas, o naturalismo e o analogismo, sobre o que se concentra mais fortemente a exposição.

O analogismo responde por um sistema no qual os humanos pensam que tudo o que compõe o mundo, sendo elementos físicos ou morais, são descontínuos ou diferentes - tudo é singularidade. Relacionado aos outros três modelos (modos de identificação, como prefere Descola) - o animismo, totemismo e o naturalismo - o analogismo funda-se sobre uma hipótese pouco documentada onde impera a fragmentação generalizada que se organiza apenas por correspondências pontuais. Disso resulta que, diferentemente dos demais modos de identificação, fortemente ancorados em vasto material etnográfico, o analogismo é situado a partir de trabalhos históricos sobre a China, casos isolados no México e, sobretudo, numa hipótese foucaultiana que aparece em As palavras e as coisas, de que a Renascença foi um período de se pôr em evidência analogias entre os elementos do mundo a fim de sistematizar o emprego do pensamento.

Outra das razões pelas quais a discussão ganha fôlego no livro é que essa reforma conceitual não se restringe ao postulado desse ana- 
logismo, mas também suscita a condição de pensar no naturalismo. Com ele é completado o reposicionamento da cena filosófica ocidental, sobretudo aquela que se hegemoniza depois da Renascença. O naturalismo, em si, não é tomado como uma oposição entre natureza e cultura ou mais particularmente entre o homem e natureza, porém faz com que a interioridade do homem seja percebida como uma descontinuidade entre ele e o resto da natureza (que inclui seu próprio corpo). Trata-se de movimento que pensa a universalidade da natureza como corolário de uma diversidade de culturas e nessa reforma, esse pensée moderne aparece como sendo uma ontologia entre outras e não a regra. É claro, frise-se aqui, como o faz o próprio Descola, que ainda que ele e Bruno Latour, por exemplo, partilhem um projeto de incluir na cena da vida social os não humanos, não tornando eles uma externalidade que influencia, determina ou explica os humanos, a passagem do analogismo para o naturalismo os coloca em desacordo. Se o projeto de modernidade na obra de Latour reflete uma proliferação de híbridos, a meio caminho do natural e do social e que não deu certo, o naturalismo - que é sustentado não por uma simples separação da natureza e da cultura, mas como um acordo de grande importância e consequências intelectuais e sociais, onde se unificam diversos fenômenos sob o conceito de natureza, temos sim um processo que produz consequências verificáveis na vida prática. Em outros termos, para Descola, jamais fomos modernos. Entre outras coisas, o implicativo disso inclui reconhecer que a história da antropologia é profundamente marcada por essa cena filosófica moderna (nos seus termos, essa ontologia naturalista), sobre o que reside o próprio desafio da disciplina em pôr em evidência, sem se envergonhar. O naturalismo era o modo de pensar os outros e nisso, questões de método trazidas pelo estruturalismo - entre o que a pontuação dos limites da etnografia e da antropologia - lhe servem como alternativa, já que causalidades psíquicas, ambientais, técnicas, econômicas, políticas, etc. que viciam a explicação dos fatos sociais, devem ser colocadas em evidência etnográfica, como formas particulares de reger a compatibilidade ou a incompatibilidade das instituições, mas não devem coordenar o empreendimento antropológico em um nível maior do que o de seus contextos de realização. Tomar 
a antropologia estrutural como uma ferramenta eficaz para explicar determinados agregados é o que lhe serve de justificativa à postulação desses modelos ontológicos, ainda que tratados pela crítica como uma sorte de esquematismo. Se o questionamento da antinomia natureza e cultura na obra de Lévi-Strauss já radicalizava uma postura relativista que, até então, nos precedentes norte-americanos, não avançam além de um multiculturalismo, a operacionalização dos modelos propostos por Descola, como conjunto de diferenças entre humanos e não humanos, amplifica o potencial de simetria da análise antropológica, fazendo conversar as ontologias sem que uma seja a referência - a Sirius - explicativa das outras.

Outro ponto interessante da autorreflexão do autor refere-se ao peso de se falar em ontologias no plural, sobretudo considerando o peso dessa palavra na filosofia. Estando a antropologia às voltas com o que se tem chamado de virada ontológica, Descola reconhece que o seu investimento teórico-metodológico o coloca no foro desse debate, mas entende que o termo ontologia suscita mal-entendidos, particularmente em sua evocação não estrita por meio de noções similares, como as de visão de mundo, cosmologia ou aquela que ele propriamente opta, de modo de identificação. Para ele, essa última expressão - que é recuperada de Marcel Mauss quando sugere que o homem se identifica com as coisas e identifica as coisas a si mesmo tendo em ambos o sentido de diferença e semelhança - aplica-se mais justamente ao modo de se falar em formas de compor o mundo. Ela toca no cerne de uma economia fundamental das interações com o mundo, ponto em evidência o processo em que os humanos se identificam como tais e onde dão acento às diversas formas de continuidade e descontinuidade com os demais seres para além de uma antinomia entre natureza e cultura, que não passa a ser mais do que uma variante possível. Já a ontologia, para Descola é simplesmente o resultado instituído de um modo de identificação - uma forma particular, ligada a época, lugar. Cada ontologia em um nível mais operacional comporta o que cabe na expressão cosmologia, como se exemplifica, em termos genéricos, o fato de Descola ver no perspectivismo ameríndio, sobretudo em seu regime de predação, uma cosmologia no interior de uma ontologia animista, ainda 
que sob a recusa de Eduardo Viveiros de Castro. Por fim, visão de mundo, adverte ele, é algo sobre o que prefere a evitação, já que supõe que há um mundo apenas, uma natureza, um sistema de objetos sobre o que cada cultura teria suas visões particulares. Para Descola, o mundo não é uma totalidade pronta e autossuficiente sobre o que se operam diferentes pontos de vista - o que temos é uma miríade de processos de mundificação ("processus de mondiation"). A clarificação que o autor faz sobre seu léxico faz-se como boa medida para contrapor a algumas críticas isoladas, de que falar em ontologia, na antropologia, é só um modo de substituir alguns termos cansados, notadamente, o de cultura. Virada ontológica, seja lá o que for, não é um novo culturalismo, em quaisquer que sejam os seus sentidos.

Finalmente, cabe ressaltar que o mérito de um livro baseado em entrevistas é o de dar um lugar ativo ao leitor ou ao representante dele, e Charbonnier tira grandes proveitos dessa condição, valorizando aspectos axiais, polêmicos e para muitos, até enigmáticos do pensamento de Philippe Descola e os desdobramentos que ele faz do estruturalismo levistraussiano. Assim, ainda que bastante centrado em um projeto antropológico já bem conhecido atualmente, importantes questões que demandam respostas densas fazem com que La composition des mondes ofereça uma originalidade que abre novas luzes de discussão, até mesmo entre os leitores mais familiarizados com a sua obra. 